\title{
Diagnóstico pré-natal e parto transpelviano na osteogênese imperfeita: relato de caso
}

\author{
Prenatal diagnosis and vaginal delivery in osteogenesis imperfecta: a case report
}

Alex Sandro Rolland de Souza ${ }^{1,2,3}$, Alexandre Silva Cardoso ${ }^{4}$, Marcelo Marques de Souza Lima ${ }^{2,3,5}$, Gláucia Virgínia de Gueiroz Lins Guerra²

\section{RESUM0}

A osteogênese imperfeita é doença do tecido conjuntivo devida a anormalidades quantitativas ou qualitativas do colágeno tipo I, transmitida geneticamente, por gene autossômico dominante ou recessivo, que determina fragilidade óssea. Relata-se o caso clínico de paciente de 19 anos, primigesta, encaminhada ao setor de medicina fetal com ultra-sonografia pregressa evidenciando encurtamento de extremidades fetais. $\mathrm{Na}$ avaliação morfológica, identificou-se contorno craniano irregular com deformidade à compressão do pólo cefálico, membros com rizo e mesomelia, rarefação óssea e encurvamento de ossos longos (fraturas). A paciente evoluiu com parto transpelviano na $35^{\mathrm{a}}$ sem ana de gestação. O recém-nascido apresentou Apgar de 6 no $1^{\circ}$ minuto e 8 no $5^{\circ}$ minuto, sexo masculino, pesando 1.990 gramas. Observado crânio irregular, ossificação diminuída, esclera azulada e fraturas consolidadas com deformidades em todos os membros. O recém-nascido apresentou boa evolução neonatal, recebendo alta hospitalar em boas condições. O diagnóstico pré-natalé de grande importância para adequado acompanhamento da gravidez e a via de parto transpelviana não ocasionou piora do prognóstico neonatal, pois não foram diagnosticadas fraturas recentes.

PALAVRAS-CHAVE: Osteogênese imperfeita; Diagnóstico pré-natal; Parto normal; Ultrasonografia; Relatos de casos [tipo de publicação].

\section{ABSTRACT}

Osteogenesis imperfecta is a connective tissue disorder due to quantitative and qualitative anomalies in type 1 collagen, genetically transmitted by a dominant or recessive autosomal gene, leading to bone fragility. We report a case of a 19-yearold G1 PO patient referred to our institution following a screening ultrasound that demonstrated short limb fetal extremities. A level 3 scan was performed which evidenced an irregular cranial shape and compression of the cephalic pole with moderate transducer pressure. Limb shortening, decreased echoes and fractures of long bones were found on our scan evaluation. A vaginal delivery occurred at 35 w eeks of gestation. The male newborn, weighing $1.990 \mathrm{grams} \mathrm{had} 6$ and 8 in Apgar scores. The neonate was clearly abnormal, presenting irregular cranial shape, with poor ossification on X-ray, blue sclera, fractures and limb deformities. Postnatal evaluation was satisfactory and the neonate was discharged in good conditions. Prenatal diagnosis is important for an adequate pregnancy follow-up. Postnatal outcome was not related to vaginal delivery, as there were no recent fractures in the newborn.

KEYWORDS: Osteogenesis imperfecta; Prenatal diagnosis; Natural childbirth; Ultrasonography; Case reports [publication type]

\section{Introdução}

Na osteogênese imperfeita ocorre distúrbio hereditário do tecido conjuntivo, sendo evidenciadas anormalidades quantitativas ou qualitativas do colágeno tipo $\mathrm{I}^{1}$. Este colágeno é a proteína mais abundan-

\footnotetext{
Centro de Atenção à Mulher - Setor de Medicina Fetal do Instituto Materno Infantil Prof. Fernando Figueira - SEMEFE - IMIP - - Recife (PE) - Brasil.

1 Pós-graduando (Mestrado) em Saúde Materno Infantil do Instituto Materno Infantil Prof. Fernando Figueira - IMIP - Recife (PE) - Brasil.

2 Preceptor da Residência em Ginecologia e Obstetrícia do Instituto Materno Infantil Prof. Fernando Figueira - IMIP - Recife (PE) - Brasil

3 Preceptor da Residência em Medicina Fetal do Instituto Materno Infantil Prof. Fernando Figueira - IMIP - Recife (PE) - Brasil.

4 Médico Residente em Medicina Fetal do Instituto Materno Infantil Prof. Fernando Figueira - IMIP - Recife (PE) - Brasil.

5 Pós-graduando (Mestrado) em Obstetrícia pela Universidade Federal de São Paulo - UNIFESP - São Paulo (SP) - Brasil

Correspondência: Alex Sandro Rolland de Souza

Av. Rui Barbosa, 579, apto. 406 - Bairro Graças - 52011-040 - Recife - PE - Telefone: (81) 3221-7924 - e-mail: alexrolland@uol.com.br
} 
te no osso, responsável por $90 \%$ do colágeno do corpo, e é o componente em maior quantidade na pele ${ }^{2,3}$.

O colágeno tipo I é formado por duas cadeias denominadas de $\alpha 1$ e $\alpha 2$, as quais são codificadas por genes dos cromossomos 7 e 17, respectivamen$\mathrm{te}^{2,3}$. Mutações em um desses genes são as responsáveis pelo defeito na sua biossíntese e são consideradas o principal fator fisiopatológico da osteogênese imperfeita ${ }^{2,3}$.

Os pacientes afetados pela osteogênese imperfeita apresentam expressão clínica variada dependendo do tipo da doença ${ }^{4}$. Entretanto, existem algumas características clínicas mais comuns, como: fragilidade óssea, a qual determina arqueamento, fratura e o calibre aumentado, devido às fraturas consolidadas e escleras azuladas, devido a camada de colágeno encontrar-se mais fina, permitindo a visibilidade do pigmento intra-ocular. A surdez pode ocorrer em aproximadamente 42 a 58\% dos casos e é devida ao colabamento do conduto auditivo, que causa pressão no nervo auditivo quando ele emerge do crânio ${ }^{5}$. A pele fina está associada à facilidade de apresentar equimoses ou hematomas. Ocorre dentiogênese imperfeita e os dentes quebram-se facilmente, são propensos a cáries, as restaurações não se fixam bem e é comum a coloração marrom-amarelada ou azul translucente, decorrente da deficiência da dentina ${ }^{6}$. A baixa estatura é devida às deformidades, principalmente dos membros inferiores. O crânio é, aparentemente, maior em relação ao corpo, mas não em relação à idade. As anormalidades ósseas incluem deformidade da coluna vertebral, decorrente da osteoporose, compressão das vértebras por fraturas e hiperfrouxidão ligamentar; rosto com formato triangular, devido ao calvário protuberante, o que causa desproporção craniofacial; hipermobilidade articular, devido à frouxidão ligamentar; dor, aguda ou crônica, pode ser associada às múltiplas fraturas, colapsos vertebrais, osteoartrites, contraturas, deformidade ou mau alinhamento dos membros ${ }^{4}$.

A classificação mais utilizada divide a osteogênese imperfeita em quatro tipos diferen$\operatorname{tes}^{7,8}$. Entretanto, novas formas estão sendo descobertas $^{4}$. O tipo I apresenta transmissão autossômica dominante, esclera azulada, osteopenia relativamente leve, o que determina a pouca freqüência de fraturas, e surdez em torno de $30 \%$ dos casos. É a forma mais branda da doença e a mais freqüente, atingindo cerca de $80 \%$ dos casos, não havendo comprometimento da estatura final do indivíduo. É subclassificado em I-A ou I-B na presença ou ausência, respectivamente, de dentiogênese imperfeita ${ }^{4,7-9}$.
O tipo II é a forma mais grave da doença e usualmente é autossômica recessiva, apresentando-se com fraturas e deformidades ósseas intrauterinas. O recém-nascido, no geral, é prematuro ou pequeno para idade gestacional e o indivíduo afetado, na maioria das vezes, evolui para o óbito dos primeiros dias a semanas de vida, por complicações respiratórias. Com um estudo radiográfico cuidadoso podem-se distinguir 3 subtipos, sendo o II-a letal antes do nascimento ou no período neonatal ${ }^{4,7-9}$

O tipo III é compatível com a vida, apresentando-se como doença autossômica recessiva. Fraturas recorrentes levam a deformidades ósseas, determinando baixa estatura, além de apresentar-se com dentiogênese imperfeita. Apesar de ocorrer deformidade dos ossos longos, articulações frouxas e escoliose, a deambulação é possivel. Os tipos II e III podem ocorrer como novas mutações dominantes ${ }^{4,7-9}$.

O tipo IV é, também, compatível com a vida, com características clínicas semelhantes às do tipo I, porém com esclera normal. Está associado com interação gênica tanto dominante como recessiva. Pode-se dividir em pelo menos cinco subtipos, conforme a utilização de critérios clínicos e histomorfométricos ${ }^{4,7-9}$.

Atualmente, acrescenta-se o tipo V, como sendo uma forma com calosidade hipertrófica e ossificação da membrana interóssea do antebraço, podendo ser levantado como diagnóstico diferencial de processos neoplásicos ${ }^{10}$, e os tipos VI e VII. Todos os três não estão associados a defeitos no colágeno tipo $\mathrm{I}^{4}$.

Outros tipos já definidos clinicamente são: a síndrome de Cole-Carpenter, osteogênese imperfeita com crânio-sinostose e proptose ${ }^{11}$; associação de osteogênese imperfeita com pseudoglio$\mathrm{ma}^{12}$; osteogênese imperfeita rizomélica ${ }^{10}$; e a síndrome de Bruck, osteogênese imperfeita com contraturas musculares ${ }^{13}$.

O diagnóstico pré-natal tornou-se importante nas anomalias congênitas para realização de um aconselhamento genético adequado. Os exames complementares utilizados para o diagnóstico prénatal da osteogênese imperfeita são os estudos radiográficos do abdômen materno, a ultra-sonografia obstétrica, a ressonância magnética, além dos procedimentos invasivos ${ }^{1,14,15}$. O diagnóstico pré-natal da osteogênese imperfeita tipo II é possível por meio da ultra-sonografia a partir da $17^{\mathrm{a}}$ semana da gestação ${ }^{1}$, sendo possível também a análise da síntese do procolágeno em células do líquido amniótico. A ultra-sonografia em três dimensões também pode auxiliar no diagnóstico prénatal $^{1}$. Entretanto, apenas o método de biologia 
molecular e o estudo genético podem confirmar o diagnóstico pré-natal ${ }^{15}$.

A via de parto adequada para fetos portadores de osteogênese imperfeita ainda não está definida. Devido à possibilidade teórica de lesão ao sistema nervoso central e o aparecimento de novas fraturas associadas ao parto vaginal, existe tendência de que a utilização da via cesariana seja o método de escolha ${ }^{16}$. Entretanto, alguns estudos sugerem que a via de parto é decisão do obstetra, ou seja, que a cesariana não traz nenhum benefício aos pacientes portadores de osteogênese imperfeita $^{17}$.

Diante de tais fatos, observa-se a grande importância do diagnóstico pré-natal para que se determine a melhor via de parto nas gestantes portadoras de fetos com osteogênese imperfeita, sendo importante obter também informações sobre a eficácia dos métodos diagnósticos.

\section{Relato de Caso}

M.J.M., 19 anos, gesta I, para 0, foi admitida no setor de medicina fetal da enfermaria de alto risco do IMIP em 5 de abril de 2004 com gravidez de 34 semanas e 3 dias. Apresentava exame ultrasonográfico com diagnóstico de displasia esquelética e restrição de crescimento fetal.

Negava outras queixas. Entretanto, referia ser tabagista e etilista nos finais de semana, hábitos que suspendeu no início da gestação, além de ter sido usuária de maconha (Cannabis sativa) até há 5 anos. Informa ainda que sua irmã teve feto com malformação congênita, sem saber especificar.

O exame físico geral na admissão não detectou anormalidades, verificando-se pressão arterial de $120 \times 80 \mathrm{mmHg}$. Ao exame obstétrico, observou-se útero de tônus normal, sem contrações, com $31 \mathrm{~cm}$ de altura. Feto em situação longitudinal, apresentação cefálica com batimentos cardíacos de $136 \mathrm{bpm}$. Toque vaginal apresentando colo uterino anterior, pérvio para 4 centímetros, com $60 \%$ de apagamento, amolecido e centralizado, e bolsa amniótica íntegra.

As hipóteses diagnósticas, no ato do internamento, foram de gestação única tópica de 34 semanas e 3 dias, erro de data e displasia esquelética a esclarecer.

No dia seguinte foi submetida a uma ultrasonografia morfológica, na qual foi observada gestação tópica e única com feto em apresentação cefálica. A idade gestacional ultra-sonográfica avaliada pelo diâmetro biparietal e circunferência cefálica era compativel com ultra-sonografia anterior (34 semanas e 4 dias). Índice de líquido amniótico normal (de 9). Relação CF/CA diminuída, 14,8 . A dopplervelocimetria obstétrica não mostrava alterações nos compartimentos materno, placentário e fetal. Placenta de localização anterior, grau I e medindo $32 \mathrm{~mm}$. Visualizado na morfologia fetal, contorno craniano irregular associado com deformidade à compressão do pólo cefálico ( $\mathrm{Fi}$ gura 1). A coluna vertebral era de difícil avaliação devido à estática fetal. Os membros eram visiveis em todos os seus segmentos, porém com encurtamento de todos, principalmente nas porções proximal (rizomelia) e medial (mesomelia), associado com diminuição da ossificação e alargamento dos ossos longos, bem como redundância de partes moles (Figura 2s e 3). Observou-se irregularidade do contorno dos ossos longos com encurvamento, sugerindo fraturas intra-uterinas. Foi sugerida como principal hipótese diagnóstica a osteogênese imperfeita.

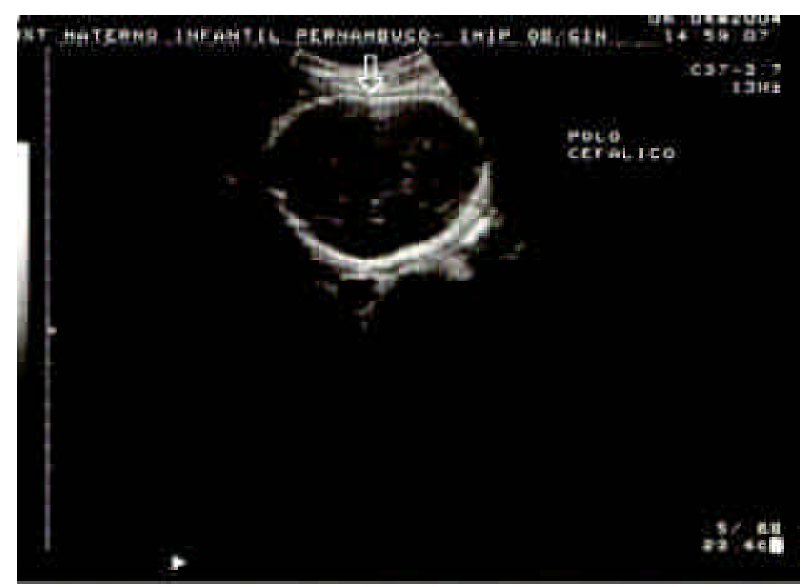

Figura 1 - Imagem ultra-sonográfica no plano axial do pólo cefálico. Observe a diminuição da ecogenicidade óssea e deformidade à compressão extrínseca durante 0 exame ecográfico (seta)

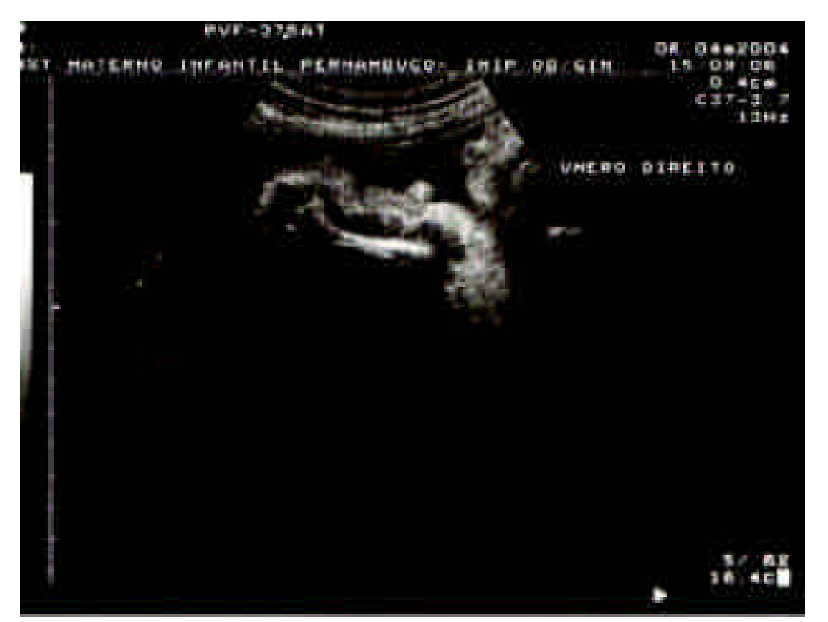

Figura 2 - Imagem ultra-sonográfica do úmero direito demonstrando encurtamento diminuição da ecogenicidade óssea, alargamento do osso e redundância de partes moles. 


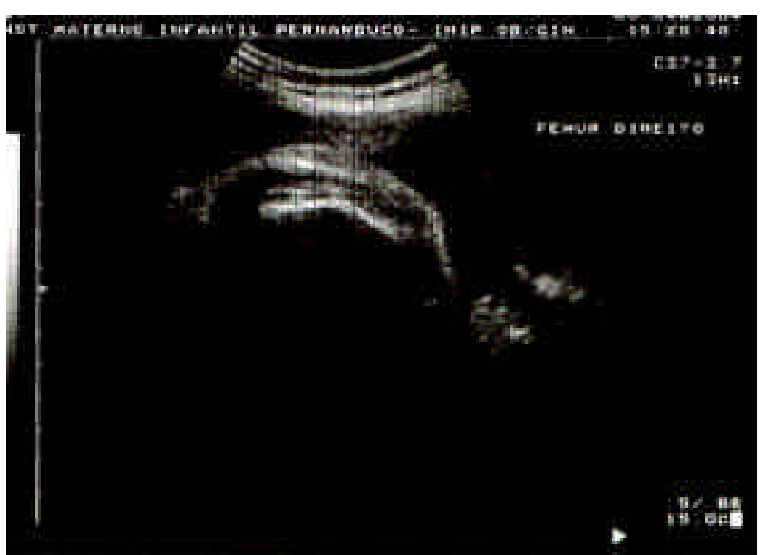

Figura 3 - Imagem ultra-sonográfica do fêmur direito com encurtamento e diminuição da ecogenicidade óssea. Observe encurvamento patológico com aspecto típico de fratura pregressa e redundância de partes moles.

Realizados exames da rotina pré-natal e ecocardiografia fetal. Os exames materno mostravam hemoglobina de $9,1 \mathrm{~g} \%$, hematócrito de $29,7 \%$ e leucograma normal. Os sumários de urina, urocultura e teste de tolerância à glicose simplificado (50 g de dextrosol) foram normais. Classificação sanguínea $O$, fator $R h$ positivo, e sorologia para HIV negativa e VDRL não reagente. Iniciada dieta rica em ferro e complementação medicamentosa com sulfato ferroso e ácido fólico diariamente. A ecocardiografia fetal foi normal.

Com 35 semanas e 4 dias, a paciente evoluiu, na enfermaria de alto risco, com queixa de dores no baixo ventre e aumento da dilatação cervical, sendo caracterizado trabalho de parto prematuro. Após discussão clínica e revisão da literatura foi decidido pela evolução do trabalho de parto prematuro e via transpelviana devido ao prognóstico reservado.

O parto transpelviano ocorreu em 14 de abril de 2004, com 35 semanas e 5 dias, sem intercorrências. O recém-nascido do sexo masculino, pesando 1.990 gramas, nasceu com estado geral comprometido, deprimido, com cianose central e Apgar de 6 no primeiro minuto e 8 no quinto minuto.

O exame físico pós-natal evidenciou escleras azuladas, fraturas consolidadas dos membros superiores e inferiores, determinando deformidades patológicas, e face triangular (Figura 4). Foi encaminhado para o berçário para acompanhamento especializado.

A paciente apresentou evolução clínica satisfatória no pós-parto, sem intercorrências clínicas durante todo o período puerperal, recebendo alta hospitalar com $24 \mathrm{~h}$.
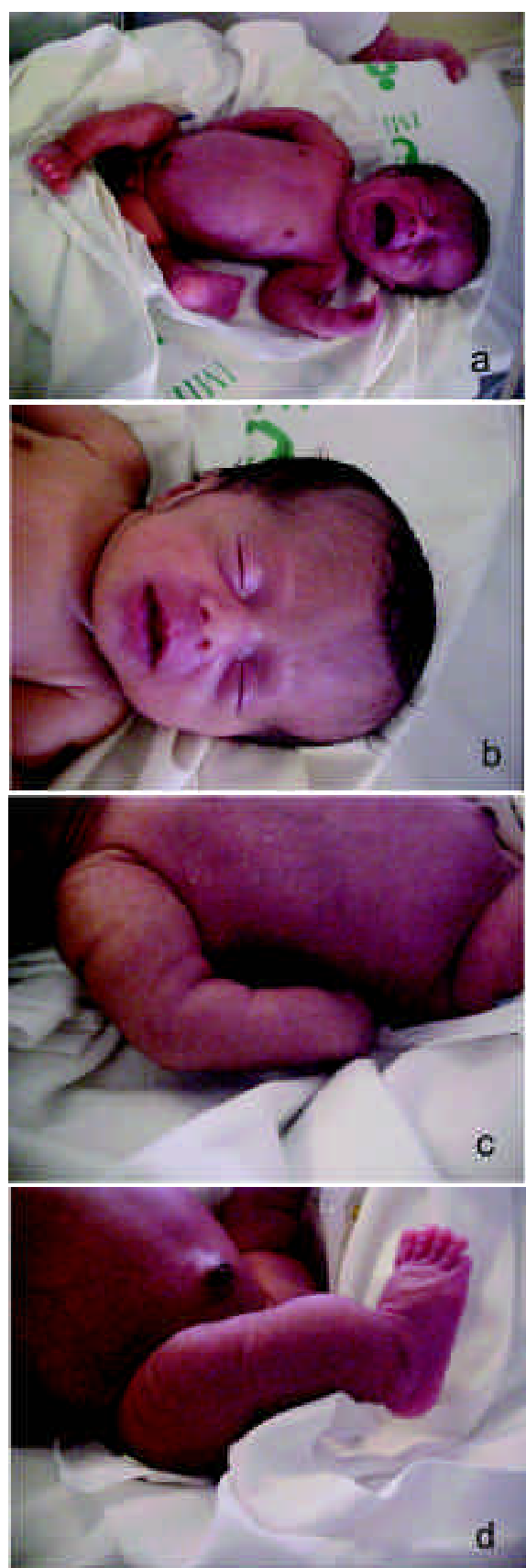

Figura 4 - Recém-nascido no primeiro dia de vida. a) Aspecto geral. b) Aspecto triangular da face. c) Deformidade de membro superior. d) Deformidade de membro inferior.

O recém-nascido também não apresentou alterações clínicas durante a internação. Estudo radiológico de todos os ossos do corpo foi realizado, sendo evidenciado: importante diminuição da calcificação dos ossos do crânio (Figura 5); membros superiores com diminuição do comprimento dos ossos longos, sendo possivel identificar redundância de partes moles; membros inferiores com alargamento, diminuição da calcificação e curvatura patológica dos ossos longos, principalmente de ambos os fêmures (Figura 6); e apenas fraturas consolidadas de clavícula direita (Figura 7) e de fibula direita ocorrida no pós-parto. 

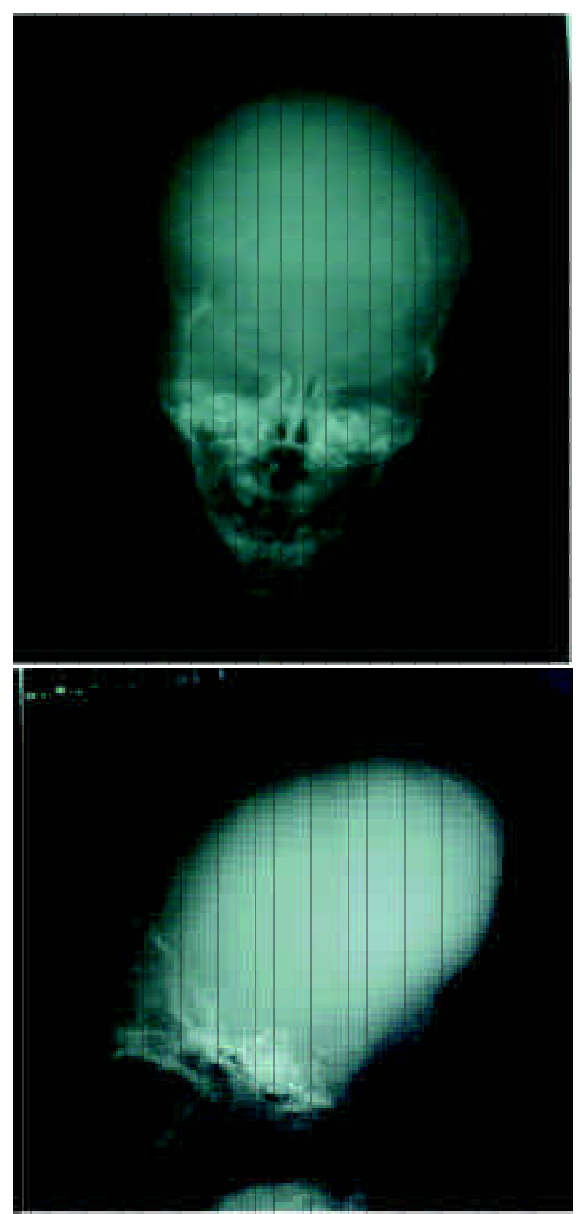

Figura 5 - Radiografia de crânio pós-natal. Incidência ântero-posterior (esquerda). Incidência lateral (direita). Note a hipotransparência dos ossos do crânio, seu aspecto triangular e as deformidades inerentes à fragilidade dos ossos do crânio. Observe ainda à direita 0 aspecto típico da dentiogênese imperfeita.
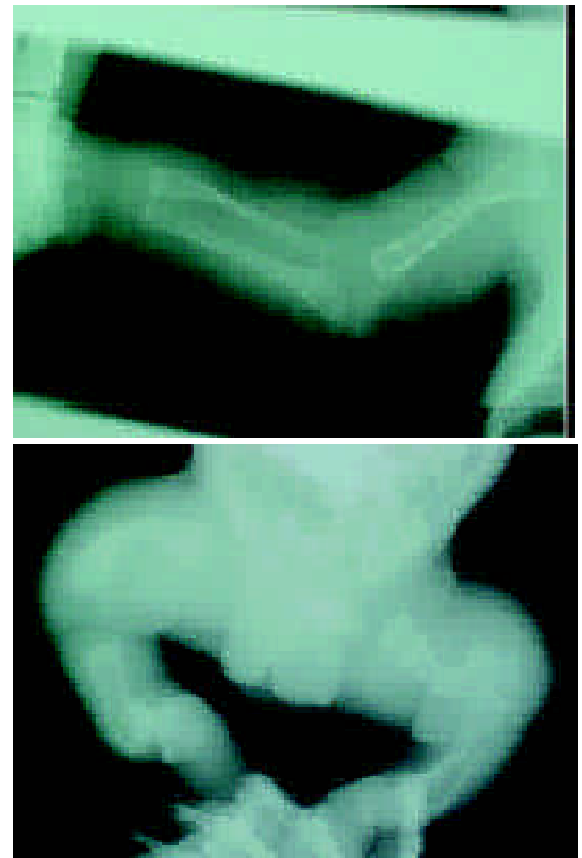

Figura 6 - Radiografia pós-natal de ossos longos. Membro superior (direita). Membro inferior (esquerda). Note a hipotransparência dos ossos longos associada com encurtamento, redundância de partes moles e encurvamento patológico, mais acentuado nos fêmures.

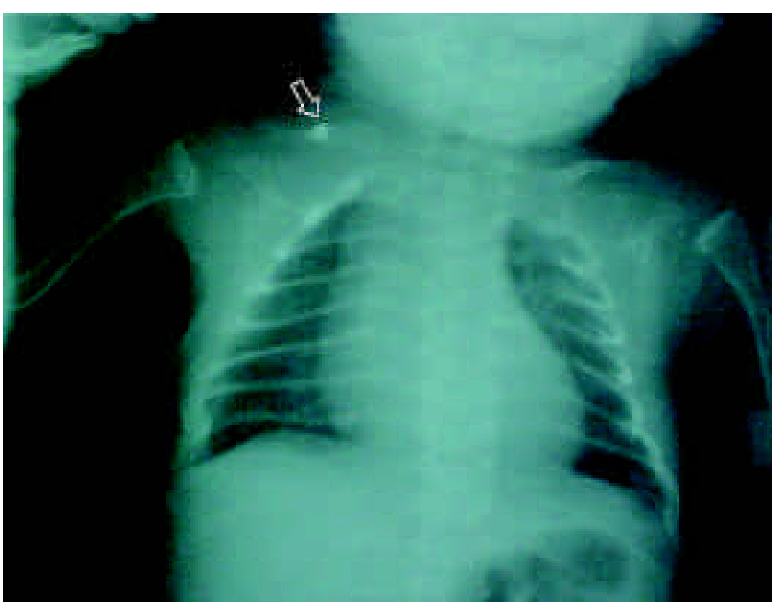

Figura 7 - Radiografia de tórax pós-natal em incidência póstero-anterior. Note a hipotransparência das costelas, as quais se apresentam mais delgadas. Evidencia-se ainda calo ósseo típico de fratura da clavícula direita (seta).

O recém-nascido apresentou boa evolução clínica, porém choroso ao toque e à mobilização, provavelmente devido à fragilidade. Houve resposta clínica satisfatória com a diminuição da manipulação e o uso diário de analgésico por via oral.

A avaliação da geneticista clínica foi realizada com 8 dias de vida. Após análise de alguns parâmetros da história clínica, como consangüinidade, paridade, sexo do recém-nascido, bem como os achados clínicos e radiológicos, como escleras azuladas, encurtamento e deformidade dos ossos longos, e crânio com ossos depressivieis à compressão, foi classificado como osteogênese imperfeita do tipo II-A ou II-B. O recém-nascido recebeu alta hospitalar com 22 dias de vida, sem apresentar outras fraturas ósseas, sendo encaminhado para acompanhamento no ambulatório de genética e endocrinologia.

Com 31 dias de vida foi admitido no setor de cirurgia pediátrica, apresentando quadro clínico de distensão abdominal importante e hérnia inguinal esquerda encarcerada, sendo submetido à cirurgia de correção. Após 4 dias de internamento hospitalar, apresentou aumento do volume da bolsa escrotal à direita com hiperemia e dor local, sendo realizado drenagem de orquite discreta e herniorrafia inguinal à direita não encarcerada. $\mathrm{O}$ recém-nascido evoluiu bem clinicamente, recebendo alta hospitalar 5 dias após a segunda cirurgia.

O acompanhamento ambulatorial foi realizado em conjunto com a pediatria, a endocrinologia, a genética, a fisioterapia e a terapia ocupacional. Em agosto de 2004 o exame radiológico de corpo inteiro demonstrava a presença de calo ósseo na clavícula direita, fraturas na $4^{\mathrm{a}}, 7^{\mathrm{a}}$, $8^{a}$ e $9^{a}$ costelas direita, curvatura de fêmur bilateralmente, fratura de tíbia bilateralmente, fratura 
de perônio e osteopenia difusa, além de colapso parcial de corpos vertebrais e presença de ossos wormianos. Evoluiu com fratura de úmero, sendo realizado proteção com um velpo. Desde dezembro de 2004 vem sendo, também, acompanhado pela pneumologia devido à dispnéia secundária a deformidades dos arcos costais.

Todas essas informações foram obtidas após consentimento informado da paciente e aprovado pela Comissão de Ética em pesquisa do Instituto Materno Infantil Prof. Fernando Figueira (IMIP), seguindo as orientações do Código de Ética Médica e observados os Princípios Éticos para Pesquisa Médica Envolvendo Indivíduos Humanos descritos na Declaração de Helsinki (1964) e atualizada pela $52^{\text {a }}$ Assembléia Geral da Associação Médica Mundial em Edimburgo (2000).

\section{Discussão}

A osteogênese imperfeita é o termo comum para um grupo heterogêneo de distúrbios hereditários do tecido conjuntivo, o qual apresenta formas letais e não letais. Sua incidência geral é de $1: 20.000$ a $1: 50.000$ nascidos vivos ${ }^{18,19}$. O caso clínico relatado foi de paciente gestante com diagnóstico pré-natal de osteogênese imperfeita a qual foi confirmada no pós-natal. A avaliação clínica da geneticista sugeriu o tipo II-A ou II-B devido à presença de escleras azuladas, encurtamento e deformidade dos ossos longos, e crânio com ossos depressiveis à compressão.

Para o acompanhamento do paciente com osteogênese imperfeita é necessária uma equipe multidisciplinar ${ }^{19}$ disposta a enfrentar desafios e recaídas terapêuticas para que o tratamento se mostre eficaz, pois é com a atuação decisiva de múltiplos profissionais qualificados que se consegue melhorar as dificuldades encontradas por esses pacientes. Observamos que ainda no período neonatal, com 31 dias de vida, o paciente retornou ao serviço e foi submetido a três pequenas cirurgias (correção de hérnia encarcerada à esquerda, herniorrafia à direita e drenagem de orquite à direita). Desta forma, deve-se lembrar a importância dos diversos especialistas envolvidos com o acompanhamento do paciente. Dentre eles, podemos citar médicos especialistas em medicina fetal, obstetras, neonatologistas, geneticistas, endocrinologistas, cirurgiões pediátricos, pneumologistas, enfermagem, psicólogos, terapeutas ocupacionais e fisioterapeutas.

Ainda não existe terapêutica medicamentosa para a osteogênese imperfeita ${ }^{8}$, porém várias outras medidas têm sido relacionadas com a melhora da sobrevida e da expectativa de vida desses pacientes. Pode-se destacar a importância dos bisfosfonatos, especialmente o pamidronato ou alendronato, com a diminuição da taxa de reabsorção, conduzindo ao aumento da densidade óssea. As dores diminuem significativamente, a mobilidade e independência aumenta e a incidência de fraturas diminui ${ }^{8,20,21}$. Os tratamentos ortopédico-cirúrgicos têm por objetivo maior manter o máximo possível da função motora ${ }^{8}$.

Em relação à polêmica discussão quanto à via de parto e ao tipo de osteogênese, tem sido sugerido que a cesariana seria menos traumática que o parto vaginal ${ }^{16,19}$. Entretanto, não existem dados para confirmar que essa concepção esteja correta. Teoricamente, existe aumento do risco de lesão do sistema nervoso central com o parto vaginal quando o esqueleto do feto é pouco mineralizado. Portanto, muitos autores indicam que seria apropriado, ao planejar um tipo de parto, avaliar o grau de mineralização do esqueleto fetal, o que pode ser verificado em parte pela intensidade e quantidade de fraturas ósseas observadas no pré-natal. Nos casos de osteogênese tipo II, em que o prognóstico é ruim, sendo considerada como doença letal ${ }^{22}$, o risco-benefício de uma cesariana é discutido com a paciente. Da mesma forma que nos tipos não letais de osteogênese, o parto vaginal pode ser uma opção sem aumento do número de fraturas no feto ${ }^{23}$.

Em estudo com 167 pacientes com fetos portadores de osteogênese imperfeita foi observada taxa de cesariana de $54 \%{ }^{17}$. Entretanto, a maioria das cesarianas foram indicadas por apresentação anômala (53\%) e menos de $15 \%$ por causa do diagnóstico antenatal de osteogênese imperfeita. Nas formas não letais da osteogênese imperfeita, 24 de 59 (40\%) tiveram o parto via cesariana e 17 de 53 (32\%) tiveram o parto via vaginal, não sendo observada diferença significativa quanto à ocorrência de novas fraturas. Entre 55 crianças com a forma mais grave da doença, 24 de 31 tiveram o parto via cesariana e 21 de 24 tiveram o parto via vaginal, sem ocorrência de mortes em até duas semanas de vida. Desta forma, os autores concluíram que o parto via cesariana não diminuiu as taxas de fratura ao nascimento em crianças com as formas não letais da osteogênese imperfeita e nem prolongou a sobrevivência dos casos das formas letais. O diagnóstico pré-natal não influenciou a via de parto na maioria das situações e a maioria dos partos por via cesariana era realizada pelas indicações obstétricas habituais ${ }^{17}$. Desta forma, devido ao estudo acima mencionado e ao prognóstico provavelmente reserva- 
do (osteogênese tipo II), foi decidido, para esta paciente, após discussão dos riscos e benefício, que a via de parto poderia ser a vaginal. Ressalta-se que após estudo radiológico pós-natal foram encontradas apenas duas fraturas (clavícula e fíbula direitas) e que estas se encontravam em consolidação, ou seja, provavelmente não foram devidas ao trauma do parto transpelviano.

Os aspectos relevantes deste relato de caso são a certeza do diagnóstico para se determinar a melhor conduta terapêutica, a gravidade da doença e o prognóstico de sobrevivência para definir a sua letalidade e o acompanhamento pré- e pósnatal adequado ${ }^{23}$. Dessa forma, pode-se julgar e definir a melhor via de parto, visto que ainda não há consenso sobre a mesma.

\section{Referências}

1. Dhouib M, Guirat N. Ostéogénèse imparfaite létale. Diagnostic anténatal. Presse Med. 2004;33(10):65860.

2. Sarathchandra P, Pope FM. Unexpected ultrastructral changes in bone osteiod collagens in osteogenesis imperfecta. Micron. 2005;36(7-8):696702 .

3. Pfeiffer BJ, Franklin CL, Hsieh FH, Bank RA, Phillips CL. Alpha 2(I) collagen deficient oim mice have altered biomechanical integrity, collagen content, and collagen crosslinking of their thoracic aorta. Matrix Biol. 2005;24(7):451-8.

4. Roughley PJ, Rauch F, Glorieux FH. Osteogenesis imperfecta - clinical and molecular diversity. Eur Cell Mater. 2003;5:41-7.

5. Streubel SO, Lustig LR. Cochlear implantation in patients with osteogenesis imperfecta. Otolaryngol Head Neck Surg. 2005;132(5):735-40.

6. Rios D, Vieira AL, Tenuta LM, Machado MA. Osteogenesis imperfecta and dentinogenesis imperfecta: associated disorders. Quintessence Int. 2005;36(9):695-701.

7. Plotkin H. Syndromes with congenital brittle bones. BMC Pediatr. 2004;4:16.

8. Rauch F, Glorieux FH. Osteogenesis imperfecta. 2004;363(9418):1377-85.

9. Whyte MP. Osteogenesis imperfecta. In: Favus MJ, editor. Primer on the metabolic bone diseases and disorders of mineral metabolism. New York: Raven Press; 1999. p. 386-9.
10. Glorieux FH, Rauch F, Plotkin H, Ward L, Travers $\mathrm{R}$, Roughley P, et al. Type V osteogenesis imperfecta: a new form of brittle bone disease. J Bone Miner Res. 2000;15(9):1650-8.

11.Cole DE, Carpenter TO. Bone fragility, craniosynostosis, ocular proptosis, hydrocephalus, and distinctive facial features: a newly recognized type of osteogenesis imperfecta. J Pediatr. 1987;110(1):76-80.

12. Beighton P. Osteoporosis-pseudoglioma syndrome. Clin Genet. 1986;29(3):263.

13.Berg C, Geipel A, Noack F, Smrcek J, Krapp M, Germer U, et al. Prenatal diagnosis of Bruck syndrome. Prenat Diagn. 2005;25(7):535-8.

14. Ruano R, Molho M, Roume J, Ville Y. Prenatal diagnosis of fetal skeletal dysplasias by combining two-dimensional and three-dimensional ultrasound and intrauterine three-dimensional helical computer tomography. Ultrasound Obstet Gynecol. 2004;24(2):134-40.

15.Teng SW, Guo WY, Sheu MH, Wang PH. Initial experience using magnetic resonance imaging in prenatal diagnosis of osteogenesis imperfecta type II: a case report. Clin Imaging. 2003;27(1):55-8.

16. Quakernack K, Beckmann M, de Moll H. Osteogenesis imperfecta in pregnancy. Geburtshilfe Frauenheilkd. 1980;40(2):180-4.

17. Cubert R, Cheng EY, Mack S, Pepin MG, Byers PH. Osteogenesis imperfecta: mode of delivery and neonatal outcome. Obstet Gynecol. 2001;97(1):669.

18. Nager GT. Fibrous dysplasia. In: Nager GT, editor. Pathology of the temporal bone. Baltimore: Williams \& Wilkins; 1993. p. 1082-148.

19.Sharma A, George L, Erskin K. Osteogenesis imperfecta in pregnancy: two case reports and review of literature. Obstet Gynecol Surv. 2001;56(9):5636.

20.Amarasena S, Lekamwasam S, Jayawardena P. Cyclical intravenous pamidronate therapy in children with osteogenesis imperfecta. Ceylon Med J. 2005;50(3):137-8.

21.Vyskocil V, Pikner R, Kutílek S. Effect of alendronate therapy in children with osteogenesis imperfecta. Joint Bone Spine. 2005;72(5):416-23.

22. Thompson EM. Non-invasive prenatal diagnosis of osteogenesis imperfecta. Am J Med Genet. 1993;45(2):201-6.

23.Kuller J, Bellantoni J, Dorst J, Hamper U, Callan N. Obstetric management of a fetus with nonlethal osteogenesis imperfecta. Obstet Gynecol. 1988;72 (3 Pt 2):477-9. 